\title{
Rapid Design of an Annealing Heat Treatment through a Combination of Microanalysis and Modeling
}

\author{
Lisa A. Deibler, Arthur A. Brown and Joseph D. Puskar \\ Sandia National Laboratories, Albuquerque, USA
}

A combined effort utilizing computational modeling and experiments was performed to optimize a heat treatment of 304L stainless steel tube in order to control final properties. A lot of 304L stainless steel tube was found to have been manufactured to a hardness higher than specification. To design a heat treatment to bring the hardness down to within specification while avoiding formation of detrimental sigma phase or $\mathrm{M}_{23} \mathrm{C}_{6}$ [1,2] would traditionally entail a large experimental study of various heat treatments. In this case, because of project timeline constraints, a heat treatment solution was needed in a matter of weeks which precluded a traditional heat treatment study and all the metallography and process control tweaks that would normally accompany such a study.

The authors had been working together on a separate project to correlate the microstructural recrystallization that evolves during forging processes with a model of recrystallization. This model had been developed and previously verified by strength measurements [3,4]. Because of the immediate nature of the tubing annealing heat treatment problem, the authors decided to adapt the forging model of recrystallization to annealing through microstructural verification.

The forging model was previously verified by mapping the amount of recrystallization in several forgings. Forging blanks began as wedges 2.5 inches on one side and 1 inch on the other, and were subsequently high energy rate forged (HERF) flat at $1600 \mathrm{~F}$, followed immediately by a water quench. The wedges were then sliced lengthwise for microstructural characterization.

Microstructural characterization in this work was performed via light optical micrographs, scanning electron microscopy, transmission electron microscopy (TEM), and electron backscatter diffraction (EBSD). For the wedge forgings, light optical micrographs were taken at regular intervals across the wedge forging, then analyzed according to ASTM E562 [5] either by systematic point count or with the assistance of CLEMEX image analysis software to manually select and fill recrystallized grains. The software then calculated the percentage of the image covered by recrystallized grains. Both methods yielded approximately the same result when performed by the same operator. In addition, internal misorientation angle obtained by EBSD [6] was used to verify light optical microscopy results.

A comparison of the microstructural analysis results for a wedge forging with the modeled microstructure is pictured in Figure 1. While the correlation is not perfect, it gave the authors confidence that the model was robust enough to apply to the tubing heat treatment issue.

In order to characterize the recrystallization model for the tubing microstructure, a series of heat treatment experiments were performed, the resulting recrystallized volume fraction was measured, and the model was fit to the data. After verification of the model for partially annealed tubing, the model was used to optimize the amount of time at temperature to achieve the desired hardness. Thermocouple data from a furnace survey was then fed through the model to determine if all tubing within the furnace would fall within specification despite variations in temperature with furnace location. 
TEM examination along with light optical microscopy allowed for determination of an approximate time-temperature-transformation (TTT) curve for the formation of chromium carbides during the heat treatment. Figure 2 shows TEM electron dispersive spectroscopy results indicating the presence of chromium and also the approximate TTT curve generated.

With a combination of heat treat experiments to initialize the model and check for detrimental precipitate formation and modelling to determine process optimization, a heat treatment for softening 304L tubing was designed far more rapidly than would have been possible with heat treating experiments and microstructural examination alone.

\section{References:}

[1] A.F. Padilha, R.L. Plaut, and P.R. Rios. ISIJ International 43 (2003) p.135

[2] C.C. Tseng et al Metallurgical and Materials Transactions A 25A (1994) p.1147

[3] A.A. Brown and D.J. Bammann. International Journal of Plasticity 32-33 (2012) p.17

[4] A.A. Brown et al. Proceedings of the SEM Conference, 2010, pp.51-56. .

[5] ASTM International, “ASTM E562” (2011)

[6] H. Lu, P. Sivaprasad, and C.H.J. Davies. Materials Characterization, 51 (2003) p.293

[7] The authors acknowledge Alice Kilgo, Marty Cunningham, Peter Duran, and Chuck Walker. Sandia National Laboratories is a multi-program laboratory managed and operated by Sandia Corporation, a wholly owned subsidiary of Lockheed Martin corporation, for the U.S. Department of Energy's National Nuclear Security Administration under contract DE-AC04-94AL85000.
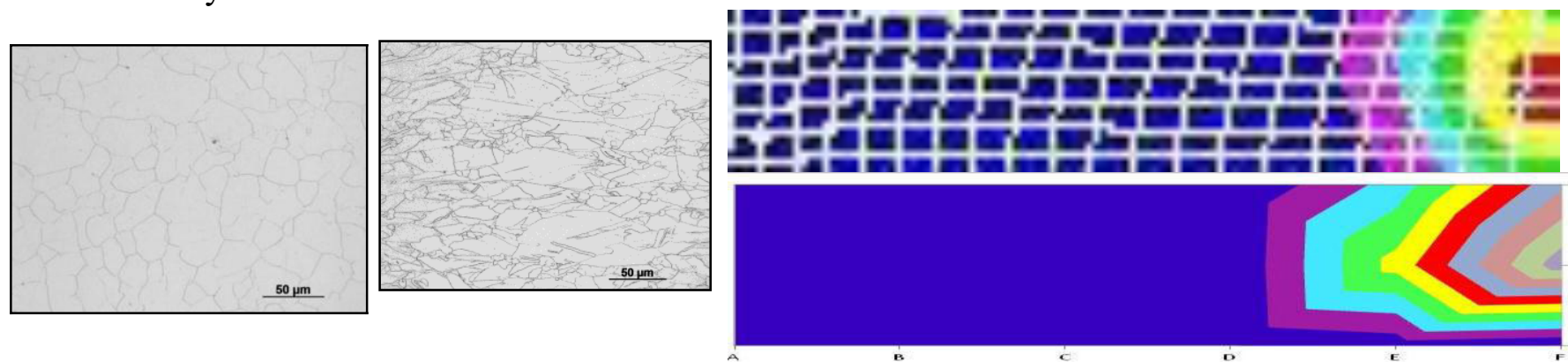

Figure 1. Microstructures from various locations within a wedge torging and comparison of experimental microstructural measurements with modeling results.
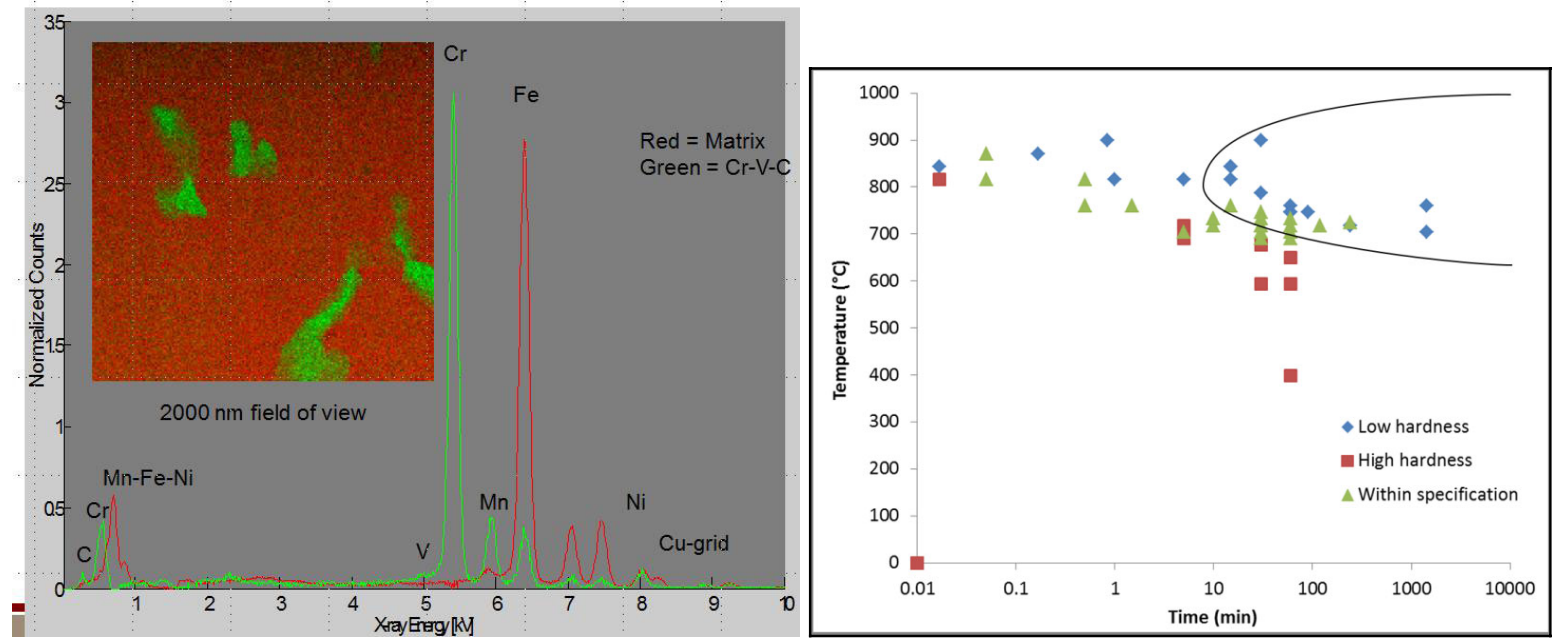

Figure 2. Examples of chromium carbides, and approximate TTT diagram for their formation. 